\title{
Electrical and Ferroelectric Properties of Undoped and Er-Doped PZT52/48 Electroceramics Synthesized by a Polymeric Precursor Method
}

\author{
Jaime Alberto Sanchez Caceres ${ }^{a *}$ (1), Carlos Augusto Cardoso Passos ${ }^{b}$ (1) \\ ${ }^{a}$ Instituto Federal do Espirito Santo, Vitória, ES, Brasil. \\ ${ }^{b}$ Universidade Federal do Espirito Santo, Grupo de Física Aplicada, Vitória, ES, Brasil.
}

Received: November 24, 2020; Revised: August 13, 2021; Accepted: October 13, 2021

\begin{abstract}
The effect of Er on the structural and electrical properties of doped PZT 52/48 ceramics has been studied in this work. The ferroelectric properties (permittivity, ferro-paraelectric phase transition and hysteresis) of such materials are thus found to be strongly dependent on the degree of densification and structural phase development during sintering at high temperatures. In particular, the nature of the ferroelectric to paraelectric phase transition is in these materials that can be represented through the Curie-Weiss Law equation modified, appropriate for the characterization diffuse transitions. The substitution of $\mathrm{Er}^{3+}$ for $(\mathrm{Zr}, \mathrm{Ti})^{4+}$ is found to induce strong diffuse phase transition in these materials. The electrical properties reported in this work are in magnitude comparable to those exhibited by PZT52/48 materials.
\end{abstract}

Keywords: PZT-based, electrical properties, ferroelectric, dielectric properties.

\section{Introduction}

The lead zirconate titanate solid solutions, $\mathrm{Pb}\left(\mathrm{Zr}_{1-z} \mathrm{Ti}_{z}\right)$ $\mathrm{O}_{3}$, are widely recognized to represent a special group of perovskite-type $\mathrm{A}(\mathrm{B}$ 'B" $) \mathrm{O}_{3}$ ferroelectric materials with various potential applications in electroceramic and (micro) electronic devices as high permittivity and ferroelectric memories ${ }^{1-4}$. The structure and electrical properties of such solutions depending strongly on the $\mathrm{Zr} / \mathrm{Ti}$ composition ratio. The well-studied diagram phase of the PZT system is characterized by a morphotropic phase boundary (MPB) around $x=0.47$ corresponding to a transition from a tetragonal to a rhombohedra structure, intermediated by a monoclinic phase (according to recent literature), with decreasing Ti content. The chemistry compositions near MPB region show an increased capability of polarization, which make them suitable especially for nonvolatile memory ${ }^{1-4}$. In general, these and other possible applications of PZT-based materials, in bulk as well as in thin film forms, have been and still are explored over a wide range of compositions and (controlled) ion substitution ${ }^{5,6}$. When doped with $\mathrm{Er}^{3+}$ substituting for $\mathrm{Pb}^{2+}$, for instance, the PZT solid solution with the 52/48 composition early emerged as a highly promising system due to its relatively large piezoelectric effects, relaxor-type ferro-doped PZT materials, it has been stated that substitution of a small amount of $\mathrm{Er}^{3+}$ for $(\mathrm{Zr}, \mathrm{Ti})^{4+}$ increases considerably the bulk resistivity and reduces aging effects, among various effects of relevance ${ }^{3,7-10}$. Most electrical characterizations of this Er-doped PZT system have been, however, conducted mainly on thin films and/or over a restricted range of PZT compositions: the MPB region and the range of Zr-rich PZT compositions ( $x=0.03-0.04)$, the latter falling within the antiferroelectric region of the diagram

*e-mail: jcaceres.vix@gmail.com phase. The purpose of the present work is the study of the structural and (di)electrical properties of conventionally prepared Er-doped PZT ceramics having particularly the $\mathrm{Zr} / \mathrm{Ti}=52 / 48$ composition out from the conventional MPB. In the present work, the influence of Er doping is closely considered. Some previous structural and microstructural results obtained in the laboratory on the system were taken into account for developing this work.

\section{Experimental Detail}

The lead zirconate titanate $(\mathrm{Zr} / \mathrm{Ti}=52 / 48)$ synthesis is performed considering the phase diagram in the interface region of the morphotropic phase of the two solid solutions $\mathrm{PbZrO}_{3}$ and $\mathrm{PbTiO}_{3}$. The synthesis route to prepare the samples was by the polymer precursor method (Pechini method modified $)^{5,6}$. The reagents were used: Lead Acetate, Titanium Isopropoxide, Zirconium Oxide Dinitrate.

In second step, the PZT precursors were doped with Erbium Oxide. Each precursor was weighted with stoichiometry of final product, that is, $\mathrm{Pb}_{1-x} \mathrm{Er}_{x}\left(\mathrm{Zr}_{0.52} \mathrm{Ti}_{0.48}\right) \mathrm{O}_{3}$ being $x=0.0$, $0.5,1.0$ and 3.0 mole percent.

The last step was to submit the resin to two heat treatment to eliminate the part organic at $400{ }^{\circ} \mathrm{C}$ and to form the crystalline phase at $700{ }^{\circ} \mathrm{C}^{7-10}$. After that, each powder sample was pelletized in disc form with $7.0 \mathrm{~mm}$ of diameter and submitted to a uniaxial compression of $80 \mathrm{kgf} / \mathrm{cm}^{2}$ for 20 seconds. The density of samples green were equal to $43 \%$ as compared to its theoretical density $(\rho=8.006 \mathrm{~g} /$ $\mathrm{cm}^{3}$ - card \#33-0784; JCPDS).

This calcination temperature was determined by Thermal Gravimetric Analysis (TGA) and differential thermal analysis (DTA) (Netzsch TG 209) where indicated the temperature 
of maximum mass loss, the decomposition kinetics and crystallization process.

Dilatometry tests were performed to determine the ideal sintering temperature of our ceramic samples ${ }^{11,12}$. The tests were carried out with a Netzsch (DIL 402 PC) dilatometer, with a constant heating rate of $10^{\circ} \mathrm{C} / \mathrm{min}$ under synthetic air flow, in the temperature range of $25^{\circ} \mathrm{C}$ to a temperature that does not reach the melting point of material. To sintering/ densification, each sample ceramic was introduced in furnace and sintered with isothermals among $830{ }^{\circ} \mathrm{C}$ to $930{ }^{\circ} \mathrm{C}$. The density of the sintered pellets was measured by the Archimedes' method and was found to be $96-98 \%$ of its theoretical density.

The samples were characterized by X-ray powder diffraction (XRD), Impedance Spectroscopy techniques. X-ray diffraction measurements were performed using a Rigaku Rotaflex RU200B automatic diffractometer, copper $\mathrm{K} \alpha$ radiation with the parameters $(50 \mathrm{KV}, 100 \mathrm{~mA}, 1.5405 \AA$ ). Scanning electron microscopy (SEM-FEG, Supra 35 Zeiss). The aim was to evaluate the degree of densification of the materials, as well as the average size of the samples grains by applying the method of intercepts ${ }^{12,13}$, conform the standards of the American Society for Testing and Materials (ASTM 152).

Dielectric studies were realized dielectric studies using the impedance spectroscopy technique. The measurements were carried out with a Solartron SI 1260 impedance analyzer, to $f=1 \mathrm{MHz}(f=\omega / 2 \pi$ is the linear frequency $)$, and from room temperature up to $550{ }^{\circ} \mathrm{C}$. The entire process was computer controlled. The samples ceramics in disc form had their faces coated with a solution of platinum (to perform the function of electrodes), and later taken to the greenhouse release the

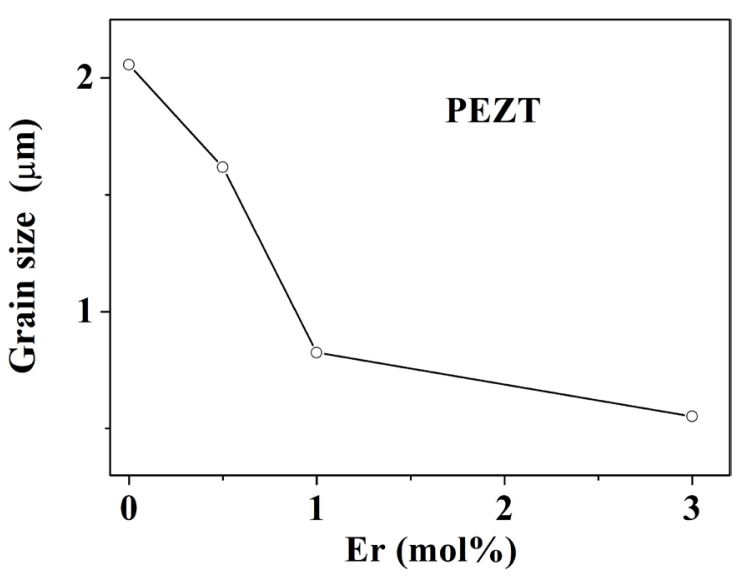

Figure 1. Average grain size (from SEM) in PZT52/48 and PEZT ceramics samples with varying Er content in the system. solvent. To realize ferroelectric hysteresis measurements were used a home-made modified sawyer-tower circuit and the frequency used was $60 \mathrm{~Hz}$ for all the samples.

For a more complete analysis of the results and to extract the resistivity values, the datas were processed in terms of impedance, while the simulation of these data through an equivalent circuit (capacitor and resistance) was performed using the professional program Zview.

\section{Results and Discussion}

In Table 1 we have shown the behavior of the final sample densities and open porosities after the sintering process. On comparing PEZT05 and PEZT30, the results indicated that the increase of Er in the system leads to a decrease of the final compaction of PEZT. We observed that the density depends on the erbium concentration in the sample and reaches its maximum value when $x=1.0$.

The average grain size of samples was determined directly from the micrographs obtained by scanning electron microscopy (SEM) where we applied the classical linear intercept method ${ }^{13}$. And the results are summarized in Figure 1. In good agreement with literature ${ }^{12}$, our results indicated that incorporation of Er in the PZT system. This dopant has allowed to an inhibition of grain growth during the material sintering.

The observed grain growth inhibition most likely results from a grain-boundary pinning process induced by the own presence of (substitutional and/or interstitial) Er ions at the grain surface. This Er-induced inhibition process considerably affected the final behavior of density, with the particularity of showing an apparent maximum (of about $7.87 \mathrm{~g} / \mathrm{cm}^{3}$ ) around $x$ $=1.0 \mathrm{~mol} \%$. That is, although strongly coarse grain materials generally result in porous bodies, too fined grain materials are expected to also show a very similar trend. If distribution of grain sizes is considered, as often found, the ideal densification of the system should be reached through an optimal mixture of coarse and fine grains, the smaller grains filling the interstices formed by the bigger grains. In Figure 1, the subsequent, apparent decrease of the Er-doped PZT ceramics average grain size above $0.0 \mathrm{~mol} \%$ of Er should result from the nucleation and a succeeding modest grain reduction.

In order to better discuss these results, firstly we chose to follow our study with an analysis of the ceramics phase development. Figure 2 shows the XRD patterns corresponding for all the samples. The XRD spectra are quite similar and our analysis confirms that the samples are monophasic and peaks are corresponding to tetragonal crystalline structure. Moreover, the XRD examination by Rietveld refinement enabled to the calculation of lattice parameters as a function of erbium concentration. The samples parameters are listed in Table 2.

Table 1. Sintering parameters and final density of the prepared PEZTceramics samples.

\begin{tabular}{cccccc}
\hline \multirow{2}{*}{ PEZT Samples $x($ Er $\%)$} & \multicolumn{2}{c}{ Sintering } & \multirow{2}{*}{$\rho_{\text {arch }}\left(\mathrm{g} / \mathrm{cm}^{3}\right)$} & \multirow{2}{*}{$(\%)$} \\
\cline { 2 - 3 } & Temp. $\left({ }^{\circ} \mathrm{C}\right)$ & Time $($ hours $)$ & 7.70 & 96.2 \\
\hline PZT52/48 & 896 & 2 & 7.82 & 97.7 \\
\hline PEZT05 & 829 & 2 & 7.87 & 98.4 \\
\hline PEZT10 & 813 & 2 & 7.68 & 96.1 \\
\hline PEZT30 & 885 & 2 & & \\
\hline
\end{tabular}


Table 2. Parameters of unit cell and some properties of $\mathrm{Pb}\left(\mathrm{Zr}_{0.52} \mathrm{Ti}_{0.48}\right)_{1-x} \mathrm{Er}_{x} \mathrm{O}_{3-x / 2}$ ceramics.

\begin{tabular}{ccccc}
\hline$x$ & 0.0 & 0.5 & 1.0 & 3.0 \\
\hline$a(\AA)=b(\AA)$ & $4.0122(7)$ & $4.0323(7)$ & $4.0285(7)$ & $4.0298(1)$ \\
\hline$c(\AA)$ & $4.1556(5)$ & $4.1352(2)$ & $4.1421(5)$ & $4.1334(5)$ \\
\hline$V\left(\AA^{3}\right)$ & $66.8989(4)$ & $67.2690(9)$ & $67.3651(2)$ & $67.3601(5)$ \\
\hline$c / a$ & $1.0356(3)$ & $1.0255(1)$ & $1.0281(9)$ & $1.0257(1)$ \\
\hline $\mathrm{R}_{\text {Bragg }}$ & 3.43 & 3.19 & 2.51 & 3.85 \\
\hline$\chi_{2}$ & 2.415 & 1.799 & 2.136 & $0.55 \pm 0.05$ \\
\hline Average grain size $(\mathrm{SEM})(\mu \mathrm{m})$ & $2.01 \pm 0,05$ & $1.65 \pm 0.05$ & 376 \\
\hline$T_{\mathrm{c}}\left({ }^{\circ} \mathrm{C}\right) 10^{6} \mathrm{~Hz}$ & 389 & 384 & 380 & 395 \\
\hline$T_{\mathrm{cw}}\left({ }^{\circ} \mathrm{C}\right) 10^{6} \mathrm{~Hz}$ & 405 & 402 & 398 & 1719 \\
\hline$\varepsilon_{T \mathrm{c}} 10^{6} \mathrm{~Hz}$ & 7930 & 5633 & 1.05 & 1.85 \\
\hline Diffusivity $(\gamma) 10^{6} \mathrm{~Hz}$ & 1.62 & 1.65 & 1.15 & 1.12 \\
\hline Activation energy $E_{\mathrm{a}}(\mathrm{eV}) 10^{6} \mathrm{~Hz}$ & 1.24 & 1.20 & & 5257 \\
\hline
\end{tabular}

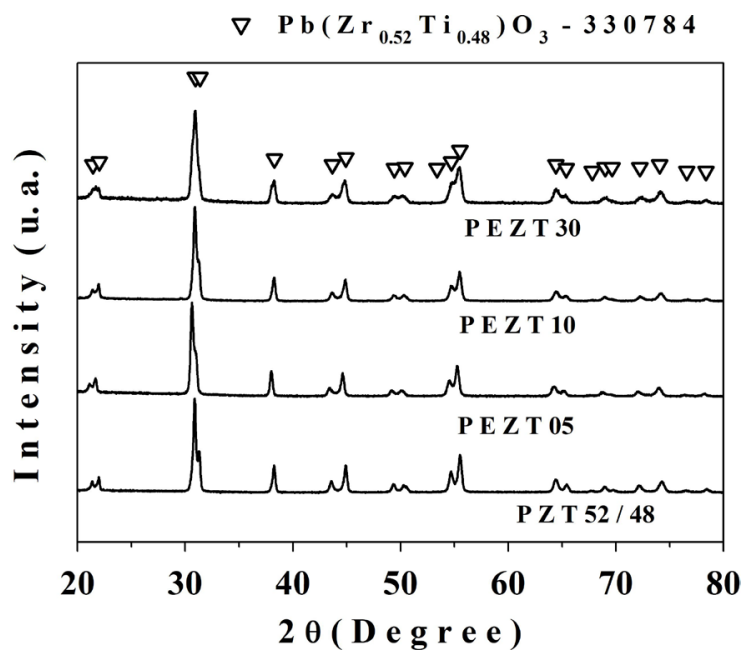

Figure 2. XRD patterns of sintered ceramics (all compositions).

We can notice in Figure 2 that there are modifications of the reflection peaks at $22^{\circ}, 45^{\circ}, 55^{\circ}$ and $65^{\circ}$. There are two explanations for such behavior. Our results indicate that the lattice parameter $a$ is higher in the erbium-doped PZT samples than in the non-doped PZT sample, see Table 2. And the lattice parameter $c$ is smaller in the erbium-doped PZT samples than in the non-doped PZT sample. The result is an expansion of the unit cell volume of Er-doped PZT samples. In our opinion, this behavior is attributed to an increase in the lattice voltage due to the difference between the ionic radius size between the host cation and the replacement cation and to a compositional disorder in the crystal (Kour and Sinha ${ }^{14}$ ). Furthermore, we observe a reduction in the degree of tetragonality $c / a$ as the concentration of Er increases. Finally, the change in the values of parameters a and c also occurs if lead is lost by the process of volatilization in the form of $\mathrm{PbO}$ during the sintering of the samples. Such losses generate lead and oxygen vacancies, which justifies changes in the unit cell.

The TGA and DTA for PZT 52/48 are shown in Figure 3. TG curves can be observed that the thermal decomposition of

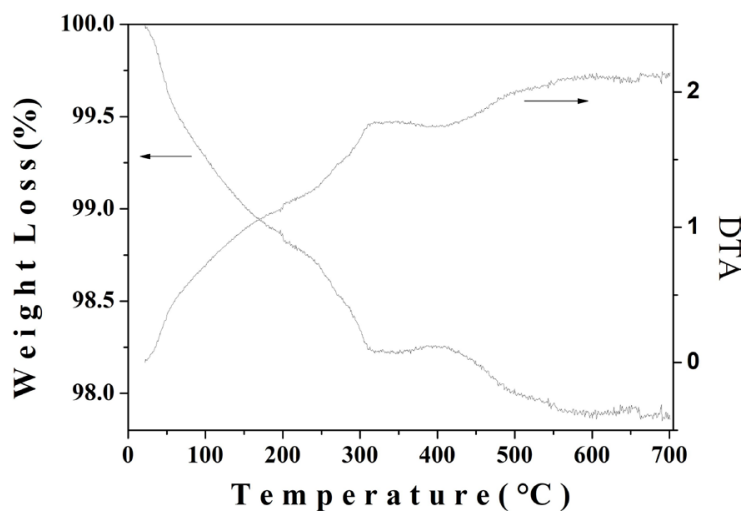

Figure 3. TGA and DTA measurements of PZT52/48 powders.

occurs with different mechanisms. From room temperature to $100{ }^{\circ} \mathrm{C}$, the weight loss can be attributed to elimination of the water. From $310{ }^{\circ} \mathrm{C}$ to $400{ }^{\circ} \mathrm{C}$ the thermal events representing to the elimination of water resultant from the ester formed between the citric acid and ethylene glycol and free citrate. It is possible to verify that the complete elimination of organic matter occurs after $600{ }^{\circ} \mathrm{C}$ indicates that PZT52/48 was crystallized. There is one exothermic peak in DTA curve at $310^{\circ} \mathrm{C}$, this peak represents the combustion of most of the organic species entrapped in PZT 52/48.

Figure 4 shows SEM micrographs of sintered PEZT compounds. The grains were found uniformly distributed throughout the surface of the samples. Their average value is given in Table 1. The grain sizes decreased with increment of erbium concentration. This behavior may be associated to a grain "pinning" process, that is, low mobility of the grain boundaries during the sintering process, induced by the presence of $\mathrm{Er}^{3+}$ ions (substitutional and/or interstitial) on the grain surface.

Figure 5(a) shows the variation of dielectric constant (E) with temperature at one frequency, $10^{6} \mathrm{~Hz}$. Here, the dielectric constant increases gradually with increase in temperature up to its transition temperature $\left(T_{\mathrm{c}}\right)$ and then 

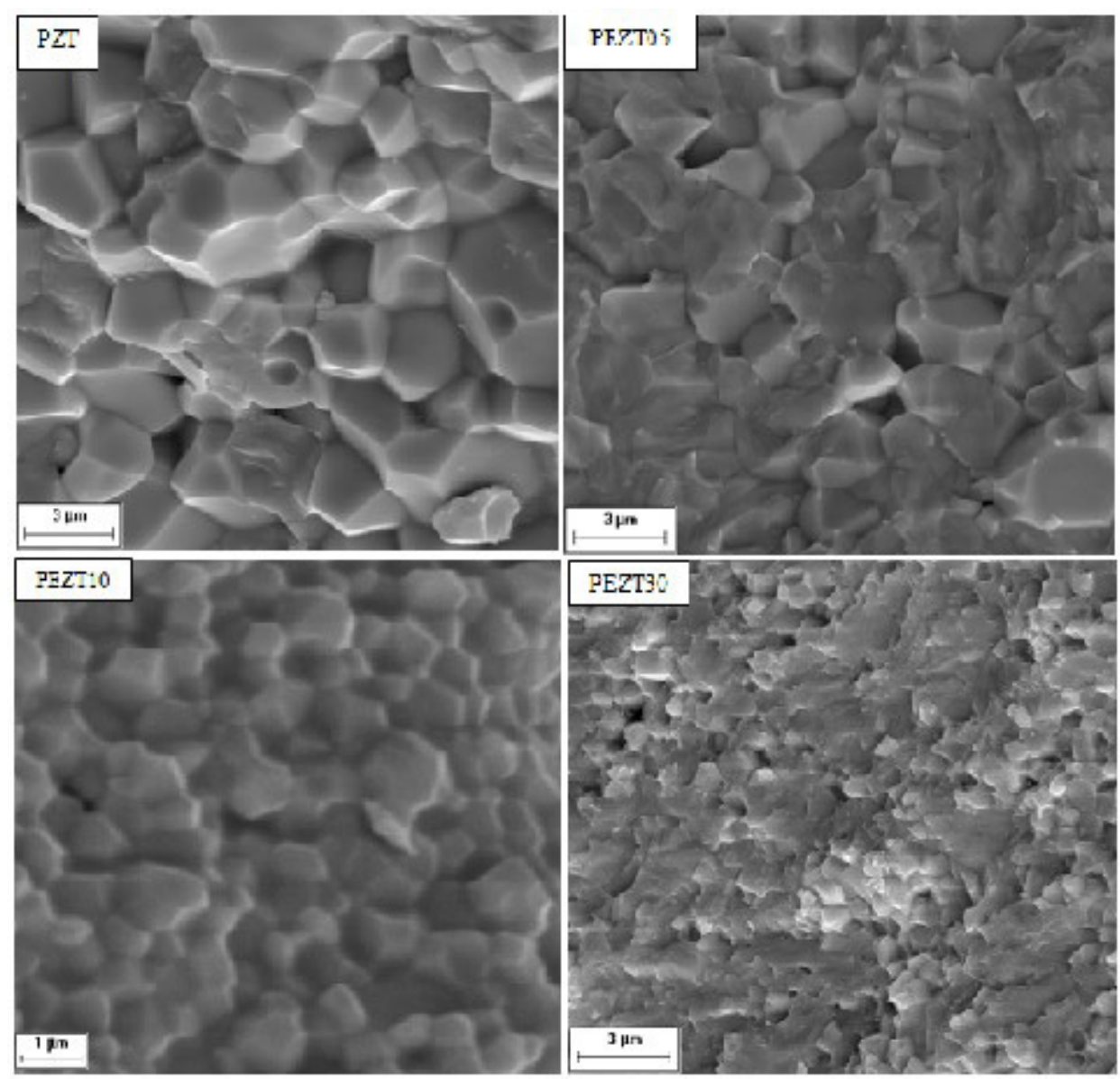

Figure 4. The SEM micrograph for all the samples.
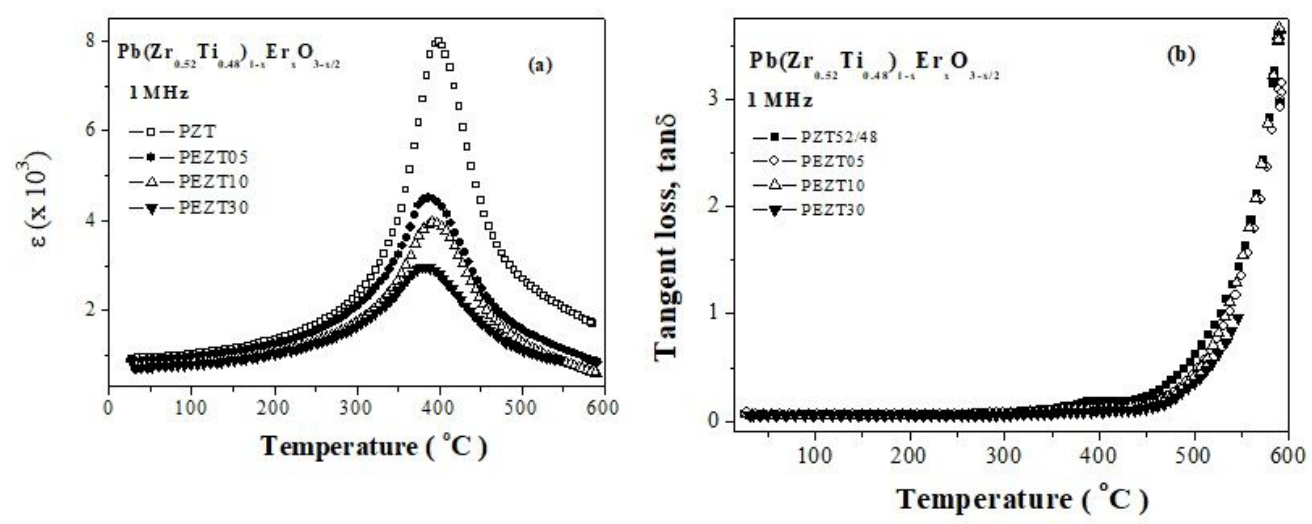

Figure 5. (a) Behavior of dielectric constant ( $(\varepsilon)$ of PZT52/48 and PEZTs' with temperature at $10^{6} \mathrm{~Hz}$, (b) Variation of tangent loss (tan ס) of PZT52/48 and PEZTs' with temperature at $10^{6} \mathrm{~Hz}$.

decreases. The region around the dielectric peak is broadened ${ }^{15}$. The broadening or diffuseness of the peaks occurs mainly due to compositional fluctuations and or substitutional disordering in the arrangement of cations in one or more crystallographic sites of the structure. This leads to micro microscopic heterogeneity in the compounds, with a different local Curie point ${ }^{15}$.
Figure $5(\mathrm{~b})$ presented the variation of $\tan \delta$ with temperature. As temperature increases, the loss tangent value increases. This increase is due to an increase of the conductivity of impurities. The value of $\tan \delta$ is higher for higher frequencies as $1 \mathrm{MHz}$, showing the normal trend of ferroelectrics ${ }^{16}$.

Plot of $1 / \varepsilon$ vs. $T$ for the PZT52/48 ceramic (around $T$ at $1 \mathrm{MHz}$ ) is depicted in Figure 6. The linear fitting for the 
curve determined that $T_{\mathrm{cw}}=405^{\circ} \mathrm{C}$ and $\mathrm{C}^{\prime}=2.77 \mathrm{X} 10^{5}{ }^{\circ} \mathrm{C}$. The Currie-Weiss $\left(T_{\mathrm{cw}}\right)$ temperature is experimentally determined through of curve extrapolation in of type $1 / \varepsilon$ vs. $T$ graphs, above $T_{c}$. For the ferroelectrics with the diffused phase transition, the dielectric behavior obeys the CurieWeiss law only in a temperature range above $T_{\mathrm{c}}$ and in high frequencies, where expect a linear trend.

The activation energy in the paraelectric region, $E_{a}$, for all the samples was calculated from the plot of $\ln \rho$ vs. $10^{3} T^{-1}$ (Figure 7), using the resistivity relation $\rho=\rho_{0} \exp (-$ $\Delta \mathrm{E} / k \mathrm{~T})$, where $k$ is the Boltzmann B constant and $\rho_{\mathrm{o}}$ preexponential factor ${ }^{1}$. The value of $E_{a}$ decreased with the increasing concentration of $\mathrm{Er}^{3+}$ (Table 2). This behavior is as follows: during the course of motion through the solid, the limited number of mobile carriers is getting trapped in relatively stable potential wells ${ }^{11}$. In a view of increase of temperature, the donor cations are taking a major part in the conduction process. The donors have created a level (i.e., band-donor level) which is much nearer to the conduction band ${ }^{11}$. However, only a small amount of energy is required to activate the donors. A little change in stoichiometry (i.e., in the metal-oxygen ratio) in multi-metal complex oxides causes the creation of large number of donors or acceptors,

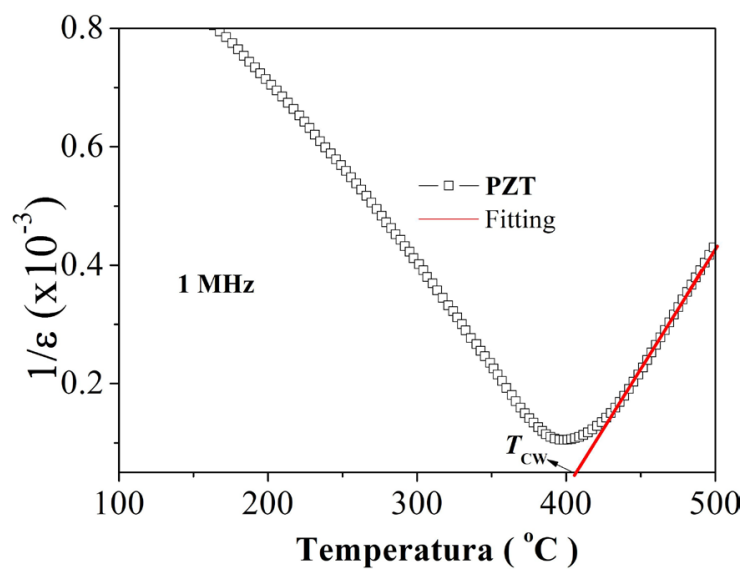

Figure 6. Plot of $1 / \varepsilon$ vs. $T$ for the PZT52/48 ceramics around $T_{\mathrm{c}}$ at $1 \mathrm{MHz}$.

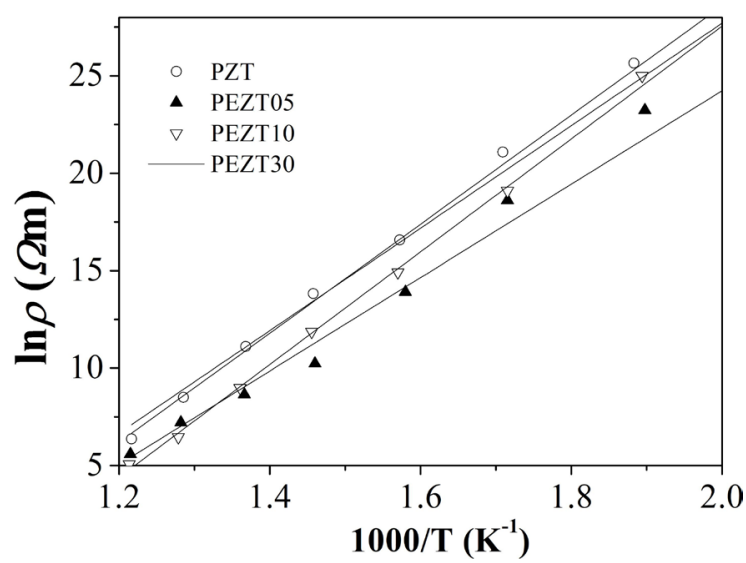

Figure 7. Plots of $\ln \rho$ vs. $1000 / T$ for the PZT52/48 and PEZTs' ceramics above $T_{\mathrm{c}}$ at $1 \mathrm{MHz}$. which creates donor or acceptor-like states in the vicinity of conduction or valence bands ${ }^{11-16,17}$. These donors or acceptors may also be activated with small energy ${ }^{18-21}$.

In Figure 8 shows the behaviors of $T_{\mathrm{c}}$ and $T_{\mathrm{cw}}$, while Figure $9\left(\varepsilon_{\max }=\varepsilon_{(T \mathrm{c})}\right)$ shows the behaviors of the maximum permittivity $\left(T_{\mathrm{c}}\right)$ and the permittivity measured at a temperature of $30^{\circ} \mathrm{C}$ as a function of the average size of grains (D) of ceramics. Such graphs reveal that $T_{\mathrm{c}}, T_{\mathrm{cw}}, \varepsilon_{\max }$ and permittivity measured at $30^{\circ} \mathrm{C}\left(\varepsilon_{30^{\circ} \mathrm{C}}\right)$ decrease with decreasing grain size. This is a known result of literature, but it still arouses a lot of curiosity in terms of interpretation. A commonly accepted hypothesis is the grain surface/volume ratio: defects associated with grain boundaries affect phase stability and ferroelectric properties that are essentially volumetric (surface/volume ratio effect). This fact is already known in nanostructured materials ${ }^{16}$. If a given compound (bulk material) does not have a magnetic order (disorder of magnetic moments), it can show spontaneous magnetization when its particles are reduced to a nanometer scale. The properties of the material are modified when the surface influences the volume of the (nano) grain, that is, ordering of the magnetic moments appears as function of the average size of grains (D) of ceramics. Another interpretation is taken in accounting to the changes caused by mass differences, electron structure and the radius among $\mathrm{Zr}$, Ti and Er ions. The substitution of the

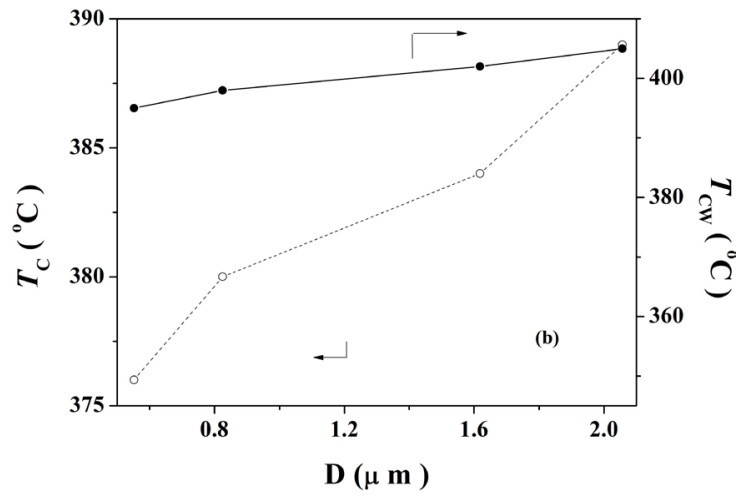

Figure 8. Dependence of the temperatures of Curie $\left(T_{\mathrm{c}}\right)$ and CurieWeiss $\left(T_{\mathrm{cw}}\right)$ with the grain size (D) of the materials studied.

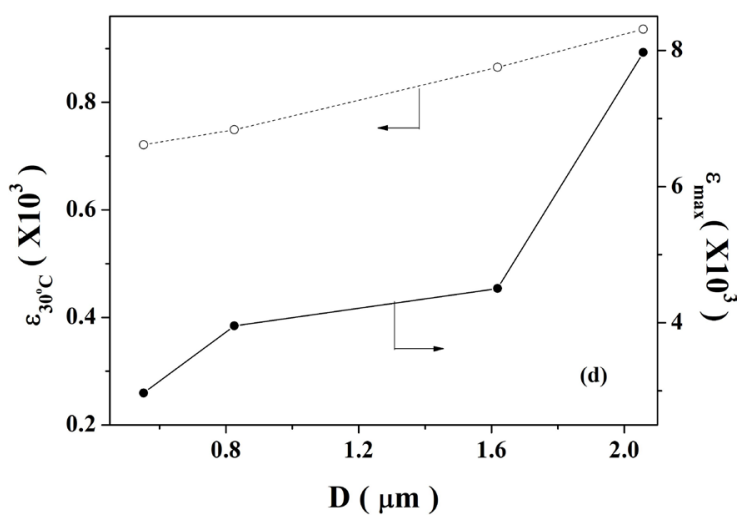

Figure 9. Dependence of maximum permittivity $\left(\varepsilon_{\mathrm{m}}\right)$ and permittivity at a temperature at $30{ }^{\circ} \mathrm{C}\left(\varepsilon_{30}{ }^{\circ} \mathrm{C}\right)$ with the grain size (D) of the materials studied. 
Table 3. Saturation $\left(P_{\mathrm{s}}\right)$ and remnant polarization $\left(P_{\mathrm{r}}\right)$ and coercive field $\left(E_{c}\right)$ determined from the measured hysteresis loop for every studied sample.

\begin{tabular}{cccc}
\hline & $P_{\mathrm{s}}\left(\mu \mathrm{C} / \mathrm{cm}^{2}\right)$ & $P_{\mathrm{r}}\left(\mu \mathrm{C} / \mathrm{cm}^{2}\right)$ & $E_{\mathrm{c}}(\mathrm{kV} / \mathrm{cm})$ \\
\hline PZT52/48 & 10.81 & 6.98 & 12.83 \\
\hline PEZT05 & 10.21 & 4.94 & 9.74 \\
\hline PEZT10 & 9.32 & 2.73 & 11.79 \\
\hline PEZT30 & 12.11 & 6.47 & 15.52 \\
\hline
\end{tabular}

$\mathrm{Er}^{3+}$ ion in site A causes a shrinkage in the tetragonality of PZT ceramics and an increase in the volume of its unit cell, as shown in Table 2. In our opinion, the $\mathrm{Er}^{3+}$ ion decreased the strength of the electric dipole moments and provoked a charge unbalance (electrons and vacancies). On the other hand, when the $\mathrm{Er}^{3+}$ ions replace the $\mathrm{Pb}^{2+}$ ions, it is occurs the formation vacancies in the site $\mathrm{A}$, and this neutralizes the charge unbalance. The replacement of $\mathrm{Er}^{3+}$ ions in the site $\mathrm{B}$ does not create $\mathrm{Pb}$ vacancies enough.

Further, the degree of disorderliness in the phase transition of the compounds can be estimated by the expression ${ }^{17}$ :

$\frac{1}{\varepsilon}-\frac{1}{\varepsilon_{\max }}=\frac{(T-T c)^{\gamma}}{C^{\prime}}$

where $\varepsilon$ is dielectric constant at temperature $T$ and $\varepsilon_{\max }$ is its maximum value at $T$ and C' Curie constant. The values of $\gamma$ (diffusivity), calculated from the graphs (Figure 10) were between 1 for normal ferroelectrics and 2 (completely disordered ferroelectrics), which shows the increase in diffuseness with the increase of $x$. The deviation of the phase transition from Curie-Weiss type can thus be interpreted as due to the occurrence of disorder ${ }^{5}$ in this system. The Curie temperature $T$ for all the samples is given in Table 2 .

The room temperature hysteresis loop of PEZT is shown in Figure 11. A high electric field $\left(\sim 20-25 \mathrm{kV} \mathrm{cm}^{-1}\right)$ was required to obtained saturation polarization. The remanent polarization $\left(P_{r}\right)$, saturation polarization $\left(P_{\mathrm{s}}\right)$ and coercive field $(E)$ were through from the hysteresis loop. It is observed that the room temperature loops for all the samples are memory-type ${ }^{12}$.

The Table 3 shows the saturation polarization $\left(P_{\mathrm{s}}\right)$, remnant polarization $\left(P_{\mathrm{r}}\right)$ and coercive electric field $\left(E_{\mathrm{c}}\right)$ determined from the ferroelectric hysteresis loop for every studied samples. At first, the ferroelectric magnitudes under study tend to increase with increase concentration of $\mathrm{Er}^{3+}$ ions. This fact can be explained on the basis of the increment of the donor when increasing the $(\mathrm{Zr}, \mathrm{Ti})^{4+}$ substitution by $\mathrm{Er}^{3+}$ atoms. From Table 3, we can see that the $P_{\mathrm{r}}, E_{\mathrm{c}}$ and $P_{\mathrm{s}}$ values show a decrease for PEZT05 and PEZT10 Er doping compared to the undoped PZT. This indicates that the degree of irreversible domain wall motion shows an increase after doping and the materials gets soften after $1.0 \%$ doping. However, for $3.0 \%$, the $P_{\mathrm{r}}, E_{\mathrm{c}}$ and Ps values are bigger than that of others samples and this indicates that when the doping concentration is increased further, this results in a slight hardening of the material. For the undoped PZT, permittivity

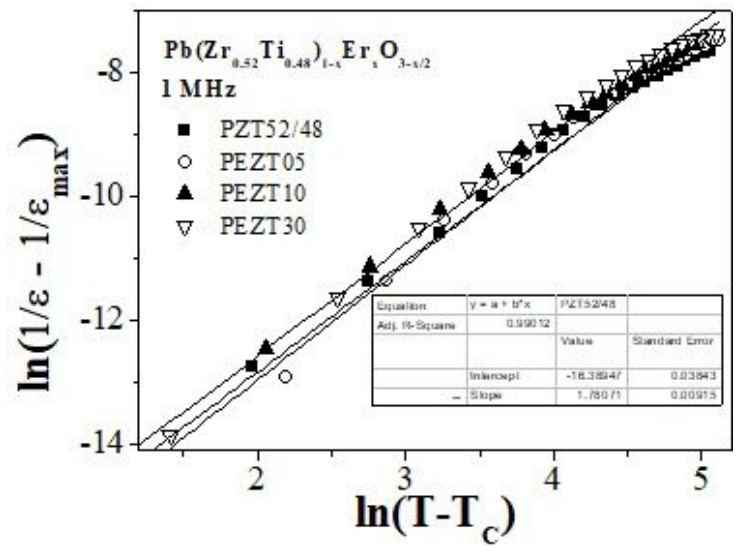

Figure 10. Variation of $\ln \left(1 / \varepsilon^{\prime}-1 / \varepsilon_{\max }^{\prime}\right)$ vs. $\ln (T-T \mathrm{c})$ of PZT and PEZT at $10^{6} \mathrm{~Hz}$.

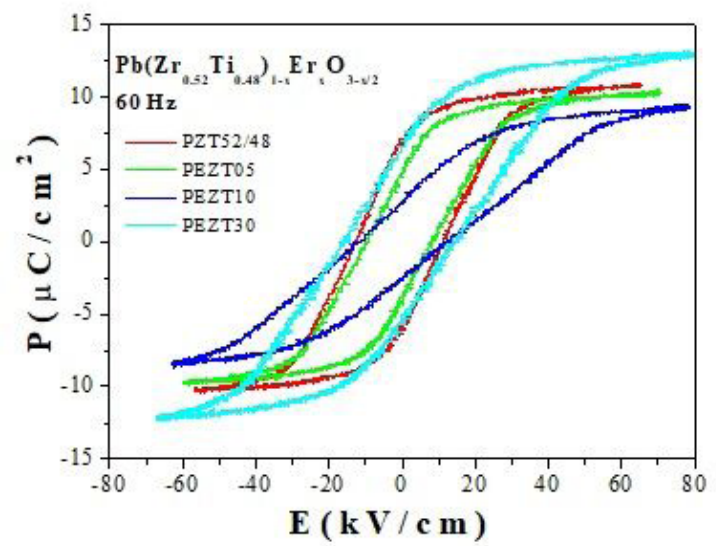

Figure 11. Room temperature $P-E$ hysteresis loop of PZT and PEZT at $60 \mathrm{~Hz}$ for $x=0.0, x=0.5, x=1.0$, and $x=3.0$.

is the maximum at room temperature compared to the doped. This is due to the fact that as the permittivity increases, it will be easier for an electric field to affect the polarization state of any ordered array of ferroelectric domains and so the $P_{\mathrm{r}}$ and $E_{\mathrm{c}}$ values are less than that for the doped samples. However, while going from $3.0 \% P_{\mathrm{r}}, E_{\mathrm{c}}$ and $P_{\mathrm{s}}$ values show increase and this may be attributed to the internal strain caused due to heavy doping ${ }^{22-24}$.

\section{Conclusions}

The PEZT ceramics of the compositions $\mathrm{Pb}\left(\mathrm{Zr}_{0.52} \mathrm{Ti}_{0.48}\right)_{1 \text { - }}$ ${ }_{x} \mathrm{Er}_{x} \mathrm{O}_{3-x / 2}(x=0.0,0.5,1.0,3.0)$ synthesized from a polymeric precursors process showed very fine and homogeneous structure. There is no change in the basic crystal structure of PZT for Er substitution with concentration until to $\mathrm{x}=3.0$. Er doping has been found to strongly influence phase development and electrical responses of Er-doped PZT 52/48 ceramics. Er shows a clear trend of reducing temperature $\left(T_{\mathrm{c}}\right)$ of maximum permittivity $\left(\varepsilon_{\max }\right)$, while increasing slightly the diffuse nature of the ferroelectric to paraelectric phase transition. The PEZT system as a whole is stated to indeed show poor diffuse phase transition characteristics, provided that the introduction of Er is achieved 
into the non-ferroactive (Zr,Ti) sites. In addition, this work shows that the final materials density combined with phase development also influence notably the overall material dielectric properties permittivity, hysteresis parameters and electromechanical coefficients).

\section{Acknowledgments}

The authors gratefully acknowledge financial supports from CAPES, Brazilian research-funding agency, and the Institute of Physic of São Carlos, University of São Paulo.

\section{References}

1. Samanta S, Sankaranarayanan V, Sethupathi K, Rao MSR. Enhanced ferroelectricity in PLZT ceramic by precise Ladoping, minimizing pyrochlore phase and lead loss. Vacuum. 2018;157:514-23.

2. Mirzaei A., Bonyani M, Torkian S. Effect of $\mathrm{Nb}$ doping on sintering and dielectric properties of PZT ceramics. Process Appl Ceram. 2016;10(3):175-82.

3. Wang L, Bai W, Zhao X, Ding Y, Wu S, Zheng P, et al. Influences of rare earth site engineering on piezoelectricand electromechanical response of $\left(\mathrm{Ba}_{0.55} \mathrm{Ca}_{015}\right)\left(\mathrm{Zr}_{01} \mathrm{Ti}_{0.9}\right) \mathrm{O}_{3}$ lead free ceramics. J Mater Sci Mater Electron. 2020;31:6560-73.

4. Bochenek D, Niemiec P. Microstructure and physical properties of the multicomponent PZT type ceramics doped by calcium, sodium, bismuth and cadmium. Appl Phys, A Mater Sci Process. 2018; $124: 775$.

5. Stenger CGF, Burggraaf AI. Study of phase transitions and properties of tetragonal $(\mathrm{Pb}, \mathrm{La})(\mathrm{Zr}, \mathrm{Ti}) \mathrm{O} 3$ ceramics - II: Diffuse phase transitions and thermodynamics. J Phys Chem Solids. 1980;41(1):25-30.

6. Pechini MU. Method of preparing lead and alkaline earth titanates and niobates and coating method using the same to form a capacitor. United States patent US 3330697. 1967, Jul 11.

7. Buckner DA, Wilcox PD. Effect of calcining on sintering of lead zirconate-titanate ceramics. Am Ceram Soc Bull. 1972;51:218-22.

8. Webster AH, Weston TB, Bright Norman FH. Effect of PbO deficiency on the piezoelectric properties of lead zirconate titanate. J Am Ceram Soc. 1967;50:490-1.
9. Crusm AT, Halloran JW. Fabrication of micro configured multicomponent ceramics. J Am Ceram Soc. 1998;81(4):1053-7.

10. Lee WH, Tseng TY, Hennings DFK. Effects of calcination temperature and $\mathrm{A} / \mathrm{B}$ ratio on the dielectric properties of $(\mathrm{Ba}$, $\mathrm{Ca})(\mathrm{Ti}, \mathrm{Zr}, \mathrm{Mn}) \mathrm{O}_{3}$ for multilayer ceramic capacitors with nickel electrodes. J Am Ceram Soc. 2000;83(6):1402-6.

11. Rao KRM, Rao AVP, Komameni S. Reactive PZT precursor powder by coprecipitation. Mater Lett. 1996;28(4-6):463-467.

12. Fang J, Wang J, Gan L, Chew C. Synthesis and characterization of ultrafine lead zirconate powders. Ceram Int. 1998;24(7):507-13.

13. Mendelson MI. Average grain size in the polycrystalline ceramics. J Am Ceram Soc. 1969;52(8):443-6.

14. Kour P, Sinha SK. Studies of $\mathrm{Sr}^{2+}$ ion substitution on ferroelectric and piezoelectric properties of PZT nanocrystalline. Ceramica. 2013;59:34-8.

15. Lines ME, Glass AM. Principles and applications of ferroelectrics and related materials. Oxford: Oxford University Press; 1977.

16. Pilgrim SM, Sutherland AE, Winzer SR. J Am Ceram Soc. 1990;73:3122.

17. Gurevich VM. Electric conductivity of ferroelectrics. Jerusalem: Israel Program for Scientific Translations; 1969.

18. Kingery WD. Introduction to ceramics. New York: Wiley; 1960.

19. Buchenan RC. Ceramic materials for electronics. Boca Raton: CRC Press; 1986.

20. Moulson AJ, Herbert JM. Electroceramics. New York: Chapman \& Hall; 1990.

21. Koura P, Pawan Kumar SK, Sinha SK, Manoranjan K. Electrical properties of calcium modified PZT (52/48) ceramics. Solid State Commun. 2014;190:33-9.

22. Oliveiran CA, Longo E, Varela JA, Zaghete MA. Synthesis and characterization of lead zirconate titanate (PZT) obtained by two chemical methods. Ceram Int. 2014;40:1717-22.

23. Du Z, Zhao C, Thong H-C, Zhou Z, Zhou J, Wang K, et al. Effect of $\mathrm{MnCO}_{3}$ on the electrical properties of PZT-based piezoceramics sintered at low temperature. Comp. 2019;801:27-32.

24. Han B, Zhao C, Zhu Z-X, Chen X, Han Y, Hu D, et al. Temperatureinsensitive piezoelectric performance in $\mathrm{Pb}\left(\mathrm{Zr}_{0.52} \mathrm{Ti}_{0.42} \mathrm{Sn}_{0.02}\right.$ $\left.\mathrm{Nb}{ }_{0.04}\right) \mathrm{O}_{3}$ Ceramics prepared by spark plasma sintering. Appl. Mater. Inter. 2017;9:34078-84. 